\title{
SUR LA SEMIOTIQUE DES CULTURES DE FRANÇOIS RASTIER SOBRE A SEMIÓTICA DAS CULTURAS DE FRANÇOIS RASTIER
}

\author{
Lia KURTS-WÖSTE \\ Université Bordeaux-Montaigne \\ lia.kurts@hotmail.com
}

RESUMÉ. La sémiotique des cultures, héritière de Cassirer autant que du Saussure autographe, permet aujourd'hui de repenser la responsabilité des chercheurs dans les modélisations de leurs objets et de construire une interdisciplinarité exigeante. Elle démontre la puissance fédérative de la méthodologie des sciences de la culture et du premier structuralisme en exploitant ses principes critiques, historiques, comparatistes pour aborder aussi bien les objets culturels que les disciplines qui en rendent compte. L'activité scientifique herméneutique y est repensée dans sa dimension d'acte interprétatif responsable, en reconnectant de manière originale les sphères scientifiques, artistiques et éthico-politiques à travers l'exploration des points de convergence entre humanisme, humanité et Humanités.

Mots-clés: sémiotique, linguistique, anthropologie, herméneutique, culture, œuvre (Rastier, Cassirer, Saussure)

RESUMO. A semiótica das culturas, herdeira tanto de Cassirer quanto do autógrafo Saussure, hoje permite repensar a responsabilidade dos pesquisadores em modelar seus objetos e construir uma interdisciplinaridade exigente. Ela demonstra o poder federativo da metodologia das ciências da cultura e o primeiro estruturalismo, explorando seus princípios críticos, históricos e comparativos para abordar tanto os objetos culturais quanto as disciplinas que os explicam. A atividade científica hermenêutica é repensada em sua dimensão de ato interpretativo responsável, reconectando de forma original as esferas científica, artística e ético-política por meio da exploração dos pontos de convergência entre humanismo, humanidade e Humanidades.

Palavras chave: Semiótica; linguística; antropologia; hermeneutica; cultura; obra (Rastier, Cassirer, Saussure).

\section{Situation}

La sémiotique des cultures, telle qu'elle s'élabore sous la plume de F. Rastier depuis les années 1990 dans la continuité de ses travaux de linguiste néosaussurien sur la sémantique textuelle, procède d'une théorie générale des formes culturelles et de leurs métamorphoses héritée de la Philosophie des formes symboliques d'E. Cassirer. Si les publications de F. Rastier sur la textualité et la sémantique interprétative sont nombreuses et constituent un corpus de référence dans le paysage actuel de la recherche - en particulier dans les départements de langue et de littérature - , si par ailleurs l'Introduction aux sciences de la culture publiée en 2002 aux PUF en collaboration avec S. Bouquet donnait des éléments précieux de contextualisation historique et de problématisation des enjeux concernant ce nouveau «continent» scientifique, il n'existe pas à ce jour 
d'introduction à la sémiotique des cultures qui permette une vue synthétique de son approche sémiotique, de ses rapports avec la sémantique, avec la textualité, mais aussi avec les études littéraires et l'histoire de l'art, la philosophie, l'éthique ou encore l'anthropologie. De récents ouvrages (Apprendre pour transmettre. L'éducation contre l'idéologie managériale (Paris, PUF, 2013), Créer: Image, Langage, Virtuel (Paris-Madrid, Casimiro, 2016), Mondes à l'envers (Classiques Garnier, 2018), Faire Sens. De la cognition à la culture, Paris, (Classiques Garnier, 2018), qui recueillent en partie des travaux déjà publiés mais restés plus difficiles d'accès car épars, apportent d'ailleurs des éléments donnant un éclairage complémentaire aux monographies existantes et permettent de mieux en saisir la portée et les enjeux. De fait, l'ambition globalisante de cette élaboration théorique portant sur la vie des signes, assez rare aujourd'hui pour constituer une originalité en soi, est confirmée, voire renforcée par ces récentes publications, de même que son intérêt prononcé pour les formes artistiques et la valorisation de la spécificité du fonctionnement symbolique des œuvres d'art. Une telle approche globalisante peut être considérée pour une part, dans sa dimension collective, comme relevant d'un effort pour surmonter le déficit de cohérence au sein des Sciences Humaines et Sociales, déficit résultant sans doute du succès considérable qu'elles ont connu au siècle dernier et qui les a vu croître et se parcelliser en multiples disciplines spécialisées, mais peut-être également d'une difficulté à penser la place des Humanités au sein des Sciences Humaines, et leur rapport aux sciences, à la scientificité. Quoi qu'il en soit, on ne peut que constater que les multiples disciplines des SHS peinent, voire ne cherchent aucunement, à faire émerger des vues d'ensemble, d'autant plus difficiles à construire qu'elles sont submergées par un flot incessant d'informations.

Les historiographies qui se multiplient aujourd'hui participent sans doute de cette recherche de cohérence et de lignes de forces, de même que les appels aux démarches pluri- ou inter-disciplinaires, mais un socle épistémologique assez solide pour construire des fondements critiques communs persiste à manquer. Si l'on convient généralement $\mathrm{du}$ fait que deux grands paradigmes - la communication et la cognition — s'imposent aujourd'hui au sein des Sciences de l'homme et de la société, il faut convenir, au vu de la situation que nous venons de 
rappeler, de leur difficulté à fédérer véritablement le champ de la recherche et de leur insuffisance, voire de leur inadéquation, à prendre en compte la spécificité des Humanités centrées sur les œuvres, langagières ou non langagières.

La position de la sémiotique des cultures consiste ainsi globalement à considérer que la possibilité de repenser une cohérence au sein des Sciences de l'homme et de la société passe par leur (ré)intégration dans le continent scientifique des sciences de la culture.

\section{Une démarche générale originale: un «à rebours» prospectif}

Il nous a semblé intéressant de commencer par caractériser la démarche générale dans laquelle s'inscrit cette théorie sémiotique néo-saussurienne et néocassirérienne - telle du moins qu'on peut la reconstituer par un travail de synthèse à partir de ses diverses publications scientifiques - et ce, en historicisant ses enjeux. De fait, cette démarche générale nous paraît consister en une interrogation critique des liens complexes qui existent entre les différents critères régulant la pratique scientifique dans les: consistance disciplinaire, cohérence épistémologique et critères «exogènes» (éthiques, anthropologiques, socio-historiques, philosophiques,...). Avec pour «ligne de fond» une question sous-jacente fédérant l'ensemble des problématiques: y a t-il (peut-il ou doit-il y avoir) dans les Sciences de l'homme et de la société un point de vue fédérateur, régulateur, centré sur une définition plus ou moins implicite de l'humainet/ou de ce qui vaut pour l'humain? Fr. Rastier montre que la possibilité même de poser ces questions suppose de surmonter une forme d'amnésie générale qui - par une sorte d'involution scientiste et/ou par une interprétation tendancieuse de la revendication à la liberté à l'égard des normes comme exaltation d'un sujet hypersubjectif et anhistorique conçu comme une victoire du jugement privé sur les écoles et les institutions, interprétation apparue dans les années 70 -, a perdu la capacité à penser ensemble ce que les recherches sémiotiques du début du XX siècle avaient pourtant commencé à articuler, dans le droit fil des études philologiques, en particulier de la romanistique germanique: la linguistique et les études littéraires, et plus généralement encore la linguistique et l'anthropologie. 
C'est dans ce cadre que F. Rastier interroge le caractère relativement déceptif des deux paradigmes (communication et cognition) dominant aujourd'hui les SHS: leur difficulté à orienter valablement la pensée viendrait ainsi majoritairement de leur «oubli» de cette approche par les formes symboliques qui avait pourtant fédéré plus ou moins explicitement le champ de la recherche au début du XX $\mathrm{XX}^{\mathrm{e}}$ siècle et dont $\mathrm{E}$. Cassirer peut être considéré comme une des figures emblématiques: c'est à cette approche que revenait le mérite d'avoir poser la question, via l'interrogation sur les rapports entre linguistique et études littéraires (ou «Humanités»), des liens complexes entre humanisme, humanité et Humanités ${ }^{1}$.

Nous souhaiterions ici tenter de caractériser cette démarche générale, originale et féconde par bien des aspects, non seulement par sa capacité à penser ensemble, selon des modalités à la fois héritées du passé (outre Cassirer, Warburg, Saussure, il faut citer les grands herméneutes comme Auerbach ou Panofsky) et nourries de nouveaux corpus critiques (Gilbert Simondon, André Leroi-Gourhan, les résultats des recherches récentes en neurosciences), linguistique, anthropologie, sociologie, esthétique, histoire de l'art, littérature et philosophie, comme ont pu le tenter les grands prédécesseurs comme Cassirer, Humboldt ou encore Levi-Strauss, mais aussi par la rigueur avec laquelle elle s'applique à élaborer la possibilité même d'une telle pensée globalisante en s'appuyant sur une archéologie critique des représentations, en particulier des idées linguistiques et des représentations du signe, fondant de manière remarquable une dynamique de

\footnotetext{
${ }^{1} \mathrm{Au}$ sens restreint des études de Lettres classiques et au sens large, anglo-saxon, des Sciences Humaines et Sociales, économie parfois comprise. Les Humanités Comme le note à juste titre Xavier Darcos dans la séance publique du 8 décembre 2014 de l'Académie des sciences morales et politiques, «les humanités, en français, n'ont pas le même sens que l'anglais humanities. Dans le monde anglo-saxon, cette notion désigne un vaste ensemble de disciplines universitaires: les langues et les littératures, la philosophie, l'histoire, les arts, mais aussi la géographie et même le droit. Encore faut-il préciser qu'il n'y a pas de définition unique des humanities, pas plus qu'il n'en existe des Human sciences. Celles-ci recouvrent en partie les humanities, puisque les sciences humaines anglo-saxonnes englobent des disciplines telles que la linguistique, la philosophie, l'anthropologie ou l'économie. Malgré cette relative confusion, l'usage se répand en France aujourd'hui dans les universités ou les grandes écoles, d'emprunter humanities aux Anglo-saxons, dans la définition très large qu'ils en ont, et de traduire par «humanités». Mais dans l'histoire de notre langue, les humanités ont un sens beaucoup plus restreint: c'est la partie de l'enseignement secondaire jadis fondée sur les lettres classiques, et parfois, par métonymie, l'enseignement secondaire dans son ensemble; ou bien: les langues et les littératures grecque et latine, l'étude qu'on en fait, l'amour qu'on a pour elles.»

Question dont la reprise donne d'ailleurs de quoi répondre aujourd'hui, au moins en partie, aux nouvelles questions relevant du «trans-humanisme» ou du «post-humanisme».
} 
recherche prospective sur un mouvement «à rebours » : non seulement à rebours du temps, par un effort rétrospectif que son approche historiciste suppose et impose, mais aussi à rebours des tournants proclamés, des paradigmes dominants et des parti pris idéologiques, retissant des liens complexes entre pensées d'aujourd'hui et pensées de naguère et d'autrefois avec une clairvoyance dont la puissance heuristique nous paraît utile, aujourd'hui, à la collectivité des chercheurs, à son auto-réflexion comme à sa projection dans l'avenir : c'est à ce titre que nous souhaiterions contribuer à sa diffusion et la soumettre au regard critique, regard critique que l'on considérera ici comme l'expression de la dette symbolique que l'on peut contracter à son égard. Cette démarche nous paraît à même de constituer un vecteur d'orientation de la pensée et une source d'inspiration dans toutes les disciplines des Sciences Humaines et Sociales et même au-delà, puisque celles-ci sont appelées à être repensées dans le cadre des sciences de la culture dont F. Rastier soutient le développement.

Ce dernier cite régulièrement les noms des initiateurs majeurs de ce projet des sciences de la culture: Emmanuel Kant, Friedrich Schlegel, Wilhelm von Humboldt, Ferdinand de Saussure, Franz Boas, Ernst Cassirer, Clifford Geertz, Claude Lévi-Strauss; il s'agit d'abord d'inviter à les relire...Les sciences de la culture aujourd'hui en développement dessinent en effet un nouveau réseau disciplinaire (génétique (épigénèse), éthologie, anthropologie, archéologie, psychologie, sémiotique et linguistique; cf. Introduction aux sciences de la culture, F. Rastier, S. Bouquet, Paris, PUF, 2002), sans doute appelé à intégrer de nouvelles disciplines comme la sociologie ou même certaines spécialités des neurosciences (ce qui suppose de surmonter, en particulier à travers le thème de la perception, le vieux clivage entre sciences de la nature et sciences de la culture), sur la question du conditionnement culturel des perceptions tel que l'épigénétique a pu le mettre récemment en valeur. Avec cette question de la culturalisation des perceptions, F. Rastier rejoint l'effort épistémologique, qui était aussi un effort éthique, d'un LéviStrauss, lorsqu'il appelait à la «réconciliation de l'homme et de la nature», en nuançant la rupture traditionnelle entre le monde humain conçu comme règne de la culture et celui de la nature, comme la rupture traditionnelle entre la science et les Lettres. En reprenant les thèmes du paradigme structuraliste naissant au début 
du XXe siècle, F. Rastier se pose tout à la fois en historien des idées, mais ne s'arrête pas à cette démarche, la combinant avec une exploration des vertus d'avenir d'un tel héritage, optant pour ce paradoxal «à rebours» prospectif qui le conduit à penser non seulement Saussure au futur ${ }^{2}$, mais aussi Cassirer.

\section{Les cultures ou la culture?}

Conçues comme des «espaces de normativité de l'hétérogène», les milieux culturels sont ainsi définis par leurs «spécificités». Et comme le rappelle judicieusement F. Rastier, «entre spécificités, il n’y a point de contradiction, mais seulement des différences», entre lesquelles «on peut établir [...] une même distance critique» (Créer, p.108), alors que les «identités» tendent à s'affirmer comme des tautologies narcissiques: pour éviter de penser les cultures comme des isolats essentialisés, le pluriel s'impose donc, de la même manière qu'au sein des cultures, c'est moins l'homogène que l'hétérogène (régulé) qui est mis en avant.

La sémiotique des cultures est donc une sémiotique des singularités qui se situe dans le sillage des grands projets d'anthropologie culturelle orientés vers la description des diversités qui sont apparus à la fin du XVIII ${ }^{e}$ siècle avec Humboldt et Schlegel. De fait, la diversité semble être un des critères définitoires ultimes des pratiques humaines, plus encore que l'innovation ou la transmission transmission que l'humain partage avec les «cultures» animales et qui ne suffit donc pas à définir la culture comme lieu des processus d'«humanisation» (à l'inverse de ce que suggère l'approche sémiotique des culturalistes russes comme Y. Lotman). Une éthique de la diversité est donc au principe de la sémiotique des cultures: la sémiotique des cultures prend pour objet la différence des langues et la multiplicité des systèmes de signes, la diversité et l'hétérogénéité des systèmes de signes reflétant la diversité des pratiques.

Cependant, que la diversité humaine soit le problème fondateur des sciences sociales n'exclut pas la recherche d'un point de vue unifiant qui, en s'opposant au culturalisme identitaire, complète l'épistémologie de la diversité: il s'agit donc d'éviter de tomber dans un localisme et un relativisme oublieux de sa dimension critique et qui aurait tendance à faire de sa prévention contre les

2 Voir son livre Saussure au futur, Paris, Les Belles Lettres, 2015. 
essentialisations la justification d'une certaine paresse intellectuelle consistant à laisser à d'autres la difficile question de la généralisation et de la construction d'un projet fédératif. Ainsi la sémiotique, tout en étant une sémiotique des singularités, peut-elle se penser comme une approche relevant des sciences de la culture. La sémiotique des cultures ne conçoit donc pas les cultures à rebours de la culture dans une relation d'exclusion, mais fait le choix d'élaborer une définition de la culture qui fasse à la fois droit à ses diversités, tout en maintenant la possibilité d'une même distance critique à l'égard de toutes, en essayant de se garder par ailleurs de tout ethnocentrisme. Il s'agit d'éviter de penser le singulier comme une essentialisation, mais dans le même temps, d'éviter de noyer le pluriel dans un relativisme qui pourrait confiner à l'indifférence.

Inscrire la notion de «culture» dans un programme de recherche actuel suppose d'ailleurs un travail de réhabilitation de cette dernière, dans la mesure où elle a pu faire l'objet d'une dévaluation au XX $\mathrm{XX}^{\mathrm{e}}$ siècle: soupçonnée de «criminalité colonialiste» - comme a pu l'analyser Derrida avec la notion de «colonialité» de la culture, elle s'appuierait sur un très malvenu «choc des civilisations», alors que dans la perspective retenue, «la culture est une affaire mondiale et que la notion même de littérature mondiale [et de citoyenneté mondiale] remonte au cosmopolitisme des Lumières» (p.78). Sa réhabilitation passe par sa reconstruction dans un réseau de notions et de concepts la reliant fondamentalement aux capacités de symbolisation de l'humain.

Réhabiliter la notion de «culture», c'est donc aussi avoir l'ambition de reprendre à son compte la «nouvelle compréhension de l'humain» proposée par Robert Antelme au sortir de la deuxième guerre mondiale, humanité définie «non par une âme ou des valeurs présupposées, mais par la révolte contre la déshumanisation» (p.115): ainsi les œuvres forment-elles et aident-elles à penser la culture comme un rempart essentiel contre cette déshumanisation conçue comme «désymbolisation». Par ailleurs, elles ouvrent sur une très saine «mondialisation critique» (p.128), indépendante des marchés et des prétentions à l'universalisme des dogmatismes de tous bords. Les langues sont ainsi des milieux, et ces milieux sont des œuvres collectives - qui «s'écrivent dans les œuvres» individuelles. 
Comme le souligne F. Rastier, les sciences de la culture doivent être différentielles et comparées, car une culture ne peut être comprise que d'un point de vue cosmopolitique ou interculturel: pour chacune, c'est l'ensemble des autres cultures contemporaines et passées qui joue le rôle de corpus constrastif. Les cultures ne peuvent être décrites que différentiellement, de même que les objets culturels qui les composent (textes, œuvres). Une culture n'est pas une totalité: elle se forme, évolue et disparaît dans les échanges et les conflits avec les autres.

On peut ainsi distinguer la sémiotique des cultures d'autres approches culturalistes, comme la culturologie ou les cultural studies. La culturologie slavophile, aujourd'hui fort enseignée en Russie, pose que la langue russe est le reflet de l'âme russe et qu'une conception du monde y est déposée, naturellement impénétrable au non russes. Ce thème apparaît aussi chez Heidegger par exemple avec la théorie du Grund, sol national de traditions partagées - germaniques cette fois. Le déterminisme national fait bon ménage avec des déterminismes biologiques (théories des races): ainsi le concept de «sémiosphère», proposé en 1998 par Lotman, qui connaît un grand succès, doit-il être abordé avec précaution: s'il témoigne d'une conception sémiotique de la culture et rompt avec l'idée, marxiste, qu'elle soit une simple «superstructure idéologique» qui ne modèle ni ne modifie les individus, Lotman continue à définir une culture comme un site identitaire, centré sur le nous, l'harmonie, l'intériorité, définissant un intérieur et un extérieur qui apparaît parfois comme une menace; la notion même de «sphère» suppose de fait une certaine clôture sur elle-même. Ainsi n'est-il pas prévu par ces approches que l'altérité puisse être appréciée comme telle et non dans un jeu de répulsion/assimilation, ni que dans la «traduction» ou la transposition de certains éléments une distance puisse être maintenue, car son but est précisément d'annihiler l'altérité. Ce en quoi la sémiotique des cultures ne peut suivre la culturologie.

La sémiotique des cultures se distingue par ailleurs du projet des cultural studies, qui n'a pas d'ambition scientifique, car ces dernières disent vouloir poursuivre l'entreprise de la déconstruction et critiquent ce que Derrida nomme «la colonialité essentielle de la culture». Dans cette optique, la notion même de 
«culture» serait une aliénation imposée par les dominants: il s'ensuit une essentialisation polémique des dominés.

Ce que montre la sémiotique des cultures, c'est que les Sciences de l'homme et de la société ont besoin d'une conception non ontologique de la totalité, car une culture n'est jamais autarcique et même dans des conditions d'isolement, elle se développe à partir d'une histoire partagée. Ainsi, dans cette optique, le concept de globalité semble-t-il préférable à celui de totalité, car il dessine une clôture relative et non plus absolue. La tradition philosophique, ontologique, a toujours pensé la totalité sous la forme de l'hénade ou de la monade, deux entités, l'une maximale, l'autre minimale, mais toutes deux closes et statiques. Au lieu de totalité autarcique, la sémiotique des cultures valorise une globalité interactive.

Une telle approche de la culture se fonde sur la description des langues de culture $^{3}$ (milieux traversées de normes et de valeurs), qui sont transnationales et invalident la notion de «littérature nationale» (et a fortiori la notion d' «identité nationale»). Ainsi, par exemple, l'allemand de Kafka est travaillé par le tchèque et hanté par le yiddish, et même une œuvre apparemment monolingue peut recéler un centon de traductions implicites et refondues.

\section{Bibliographie (ouvrages personnels ou en co-direction)}

Lia Kurts-Wöste, Mathilde Vallespir, Marie-Albane Rioux-Watine (dir.), Ethique et significations. La fidélité en art et en discours, en co-dir. avec Louvain-la-Neuve, Ed. Bruylant-Academia, coll. Au cœur des textes n5, 2007, 202 p.

Lia Kurts-Wöste, Mathilde Vallespir, Marie-Albane Rioux-Watine (dir.), La violence $\mathrm{du}$ logos. Entre sciences du texte, philosophie et littérature, Paris, Classiques Garnier, 2013, 186 p.

La simplicité. Enjeux et manifestations du simple en art, en co-dir. avec Sophie Jollin-Bertocchi, Anne-Marie Paillet et Claire Stolz, Paris, Ed. H. Champion, 2017, $541 \mathrm{p}$.

Lia Kurts-Wöste, Astrid Guillaume (dir.), Faire science, faire sens, éd. ISTE (à paraître, 2019).

Lia Kurts-Wöste, Des sens du corps aux formes du sens. Voies sémiotiques, Lyon, ENS éditions (à paraître, 2019)

\footnotetext{
${ }^{3}$ Les langues de culture se définissent par contraste avec les langues de service, ou langues véhiculaires, comme aujourd'hui l'anglais international (l'anglais existe aussi, bien évidemment, comme langue de culture), qui sont dépourvues de corpus et d'histoire: voir par ex. C. Joubert, Critiques de l'anglais. Poétique et politique d'une langue mondialisée, Lambert-Lucas, 2015.
} 
Lia Kurts-Wöste, Le faire-sens. Arts et anthropologie culturelle, Paris, Honoré Champion (à paraître, 2020) 